\title{
Effects of d-amphetamine on acquisition of leverpress Sidman avoidance in rats*
}

\author{
JOEL S. MILNER $\dagger$ \\ Western Carolina University, Cullowhee, North Carolina 28723
}

\begin{abstract}
Following intraperitoneal injections of d-amphetamine, male and female rats showed no drug-dose effects on response rates during the acquisition of a Sidman avoidance task. Dose-dependent differences in shock-avoidance rates were observed. Low test doses showed no effect on, moderate test doses facilitated, and high test doses inhibited shock-avoidance rates. Interresponse times (IRT) indicated that females, relative to males, emitted a greater number of well-timed responses and were facilitated by a relatively wider range of test doses. IRTs obtained during the acquisition study and data obtained from a motility experiment indicated that some mechanism other than increased motor activity, such as improved timing, was involved in amphetamine's facilitation of shock-avoidance rates.
\end{abstract}

The effect of amphetamine upon response rates during acquisition of nonavoidance responses has been extensively investigated (Minkowsky, 1939; Dispensa \& Barrett, 1941; Doty \& Doty, 1966; Quarton, 1967; Evangelista \& Izquierdo, 1971). Large amphetamine doses appear to disrupt acquisition, while smaller doses enhance learning. It remains to be determined, however, if the action of amphetamine on acquisition is simply a function of increased motor activity and, hence, a function of increased response rates, or if additional mechanisms are involved.

Several studies have investigated the effects of amphetamine on the acquisition of an avoidance response. Employing a Sidman avoidance task, Verhave (1958) demonstrated that amphetamine injections in male rats can produce large increases in response rates during acquisition. At higher test doses, some depression of response rates was noted, while still larger test doses resulted in complete elimination of responding. Domino, Caldwell, and Henke (1965), using a conditioned pole-jumping avoidance task, demonstrated that for amphetamine doses up to $1.0 \mathrm{mg} / \mathrm{kg}$, there was an increasing facilitation effect. Similarly, Bovet and Gatti (1965), employing a shuttlebox, reported that amphetamine increased the rate of avoidance responding during acquisition. These authors, however, indicated that the apparent facilitation of acquisition by amphetamine was related to an increase in intertrial responding. In contrast, Powell, Martin, and Kamano

\footnotetext{
*The author thanks Peter G. Stenn for valuable assistance in the development and completion of this research project and in the preparation of the manuscript. The author also thanks Beverly Kovacic for assistance in data gathering during the motility study, and Eugene E. McDowell, Ron P. Edwards, and Betty Price for critical comments on the manuscript. This research project was conducted at Lafayette Clinic, Detroit, Michigan, as part of the author's postdoctoral research program. Portions of this work were presented at the meeting of the American Psychological Association, September 1972.

†R equests for reprints should be sent to Joel $S$. Milner, Department of Psychology, Western Carolina University, Cullowhee, North Carolina 28723.
}

(1965), using a shuttlebox, reported a failure to find improved acquisition of a conditioned avoidance response following amphetamine administration, even though increased intertrial responding was observed.

\section{EXPERIMENT I}

The present investigation attempted to provide more extensive dose-response data on the effects of amphetamine upon acquisition rates of an avoidance response. Specifically, Experiment I investigated acquisition of leverpress responses under a Sidman avoidance schedule as a function of amphetamine dose in both male and female rats.

\section{Method}

Subjects. One hundred and thirty naive male and female rats (Wistar descendants) served as the $\mathrm{S}$ pool for the experiment. The animals arrived in the laboratory at 80 days of age. The female rats weighed from 200 to $220 \mathrm{~g}$ and the male rats weighed from 290 to $310 \mathrm{~g}$. The animals were housed individually in $17 \times 25 \times 17 \mathrm{~cm}$ hanging stainless steel cages with wire-mesh fronts and bottoms. The room temperature was maintained to $25 \pm 1^{\circ} \mathrm{C}$, with a nonreversed 12-h-on, 12-h-off light-dark cycle. Except during the training periods, laboratory chow and water were available ad lib.

Apparatus. A standard operant-conditioning chamber, with an electrifiable grid floor, was used to investigate acquisition rates. The operant chamber was placed in a sound-attenuated, ventilated box with continuous white noise present. Shock presentation was programmed by means of electromechanical programming services. The number of shocks and responses in each 15-min interval and the total number of shocks and responses/session were recorded on 11 digital counters (bins). Bins 1-10 stepped at a rate of 1 per $2 \mathrm{sec}$ and any overflow (responses occurring $20 \mathrm{sec}$ or more from a previous response) was recorded in the 11th counter, or "overflow," bin. These bins, or counters, allowed evaluation of the interresponse times (IRT). A Gerbrands cumulative recorder was employed to continuously record shocks and responses across all acquisition sessions.

Procedure. Ten minutes prior to placement in the operant chamber, each animal was injected intraperitoneally with one of 


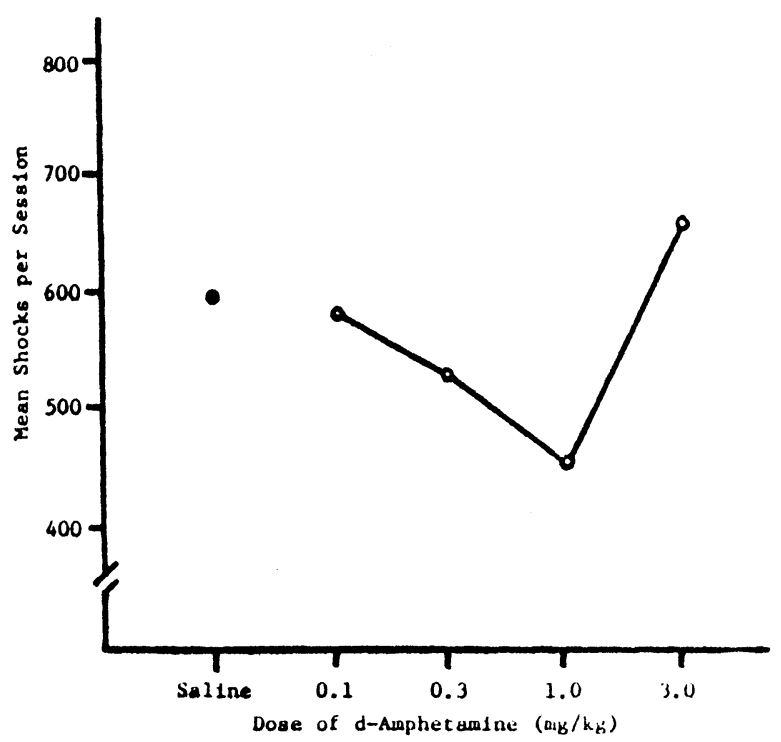

Fig. 1. Mean shock rates during acquisition sessions for all Ss as a function of saline and amphetamine dose.

the following: normal saline, $0.1,0.3,1.0,3.0$, or $10.0 \mathrm{mg} / \mathrm{kg}$ of body weight of d-amphetamine sulfate in normal saline vehicle. Ss were placed randomly in groups with the restriction that each drug condition contain six male and six female Ss. Except at the highest amphetamine dose, which proved fatal, animals were run until each drug condition contained six male and six female learners. The Sidman avoidance program was initiated as soon as the animal was placed in the operant chamber. The program delivered a shock ( $2 \mathrm{~mA}$ of 0.5 -sec duration) every $5 \mathrm{sec}$ (S-S interval $=5 \mathrm{sec}$ ) unless the $S$ pressed the lever, at which time the next shock presentation was postponed for $20 \mathrm{sec}$ $(\mathrm{R}-\mathrm{S}$ interval $=20 \mathrm{sec})$. Each acquisition session lasted $2 \mathrm{~h}$ without interruption. It was expected that some of the rats would not acquire the response within the 2-h session (Bolles \& Popp, 1964). Therefore, a criterion of 50 or fewer responses/h was employed to delete a rat as a "nonlearner." The male and female groups had six and five nonlearners, respectively, which were distributed randomly across the drug-dose groups.

\section{Results}

At the highest amphetamine dose $(10 \mathrm{mg} / \mathrm{kg}), 12$ of 13 male and female animals died during the Sidman avoidance acquisition sessions. Thus, testing of the $10.0 \mathrm{mg} / \mathrm{kg}$ group was halted and the group was excluded from analysis. Response and shock rates for saline, 0.1 , $0.3,1.0$, and $3.0-\mathrm{mg} / \mathrm{kg}$-amphetamine groups were analyzed by means of a three-factor analysis of variance with repeated measures on the third factor (Winer, 1962). The factors considered were (a) sex, (b) test dose, and (c) responses or shocks/15-min interval.

Analysis of the response-rate data indicated a nonsignificant $\operatorname{sex}(F=0.78, \mathrm{df}=1 / 50, \mathrm{p}>.05)$ and a nonsignificant test dose $(\mathrm{F}=2.26$, df $=4 / 50, \mathrm{p}>.05)$ effect. Response-rate changes across the eight 15-min intervals during acquisition were significant $(F=29.25$, df $=7 / 350, p<.01)$. A Duncan's multiple-range test (Steel \& Torrie, 1960) was employed to test for differences between the intervals. The test indicated that there was a nonsignificant $(p>.05)$ difference between each of the first five interval pairs. However, the seventh interval had significantly $(p<.05)$ more responses than Intervals 1 to 6 , and the eighth interval had significantly $(p<.05)$ more responses than all other intervals. All interactions for the response analysis were nonsignificant $(\mathrm{p}>.05)$.

For shock rates, analysis indicated a nonsignificant $(F=0.47, \mathrm{df}=1 / 50, \mathrm{p}>.05)$ sex effect. A significant $(F=2.74, \mathrm{df}=4 / 50, \mathrm{p}<.05)$ test-dose effect and a significant $(F=121.70, d f=7 / 350, p<.01)$ interval effect were observed. Figure 1 indicates the mean shock rates for all Ss as a function of test dose. A Duncan's multiple-range test was used to evaluate differences between test doses. The test indicated that the $1.0-\mathrm{mg} / \mathrm{kg}$ test dose, relative to saline, had a significantly $(\mathrm{p}<.05)$ lower mean shock rate. The $1.0 \mathrm{-mg} / \mathrm{kg}$ dose also had a significantly $(\mathrm{p}<.05)$ lower mean shock rate than the $3.0-\mathrm{mg} / \mathrm{kg}$ drug dose. A Duncan's multiple-range test was used to test for differences between the intervals. The analysis indicated that there was a nonsignificant $(p>.05)$ difference between each of the first five interval pairs. However, the seventh interval had significantly $(p<.05)$ fewer shocks than Intervals 1 to 6 , and the eighth interval had significantly $(p<.05)$ fewer shocks than all other intervals. All interactions for the shock analysis were nonsignificant ( $p>.05)$.

A third analysis was conducted on the IRT data,

Table 1

Mean IRT Responses Across Bins as a Function of Gender and Amphetamine Dose in Experiment I

\begin{tabular}{|c|c|c|c|c|c|c|c|c|c|c|}
\hline \multirow{2}{*}{$\begin{array}{c}\text { IRT } \\
\text { Bin } \\
\text { No. }\end{array}$} & \multicolumn{5}{|c|}{$\begin{array}{c}\text { Male } \\
\text { Amphetamine Dose }(\mathrm{mg} / \mathrm{kg})\end{array}$} & \multicolumn{5}{|c|}{$\begin{array}{c}\text { Female } \\
\text { Amphetamine Dose }(\mathrm{mg} / \mathrm{kg})\end{array}$} \\
\hline & Saline & 0.1 & 0.3 & 1.0 & 3.0 & Saline & 0.1 & 0.3 & 1.0 & 3.0 \\
\hline 1 & 119 & 116 & 107 & 137 & 38 & 126 & 99 & 130 & 129 & 102 \\
\hline 2 & 25 & 26 & 22 & 63 & 21 & 22 & 21 & 27 & 56 & 66 \\
\hline 3 & 22 & 20 & 32 & 39 & 24 & 14 & 22 & 19 & 48 & 54 \\
\hline 4 & 11 & 13 & 14 & 33 & 15 & 12 & 13 & 13 & 34 & 35 \\
\hline 5 & 9 & 7 & 12 & 27 & 12 & 8 & 11 & 10 & 27 & 27 \\
\hline 6 & 7 & 9 & 10 & 20 & 13 & 6 & 8 & 11 & 25 & 21 \\
\hline 7 & 5 & 7 & 9 & 19 & 10 & 5 & 5 & 7 & 18 & 14 \\
\hline 8 & 4 & 7 & 9 & 13 & 8 & 4 & 7 & 5 & 14 & 13 \\
\hline 9 & 5 & 4 & 4 & 16 & 7 & 4 & 5 & 4 & 13 & 9 \\
\hline 10 & 3 & 5 & 4 & 10 & 8 & 4 & 3 & 4 & 12 & 8 \\
\hline 11 & 214 & 202 & 208 & 159 & 144 & 193 & 201 & 213 & 169 & 123 \\
\hline
\end{tabular}


Table 2

Analysis of Variance for Simple Main Effects Between Drug Doses at Each of the IRT Bins for Each Sex in Experiment I

\begin{tabular}{rlllll}
\hline $\begin{array}{r}\text { IRT } \\
\text { Bin } \\
\text { No. }\end{array}$ & \multicolumn{2}{c}{ Male } & & \multicolumn{2}{c}{ Female } \\
\cline { 6 - 6 } \cline { 5 - 6 } & F & $\mathrm{p}<$ & & $\mathrm{F}$ & $\mathrm{p}<$ \\
\hline 1 & 4.06 & .05 & n.s. & \\
2 & n.s. & & 3.19 & .05 \\
3 & n.s. & & 3.05 & .05 \\
4 & n.s. & & 3.74 & .05 \\
5 & 3.46 & .05 & 4.27 & .01 \\
6 & n.s. & & 5.44 & .01 \\
7 & 3.14 & .05 & 6.06 & .01 \\
8 & n.s. & & 3.64 & .05 \\
9 & 6.39 & .01 & 6.55 & .01 \\
10 & n.s. & & 4.39 & .01 \\
11 & 13.05 & .01 & 7.53 & .01 \\
\hline
\end{tabular}

Note-All $d f s=4 / 25$.

which are presented in Table 1 . The factors were (a) sex, (b) test dose, and (c) IRT bin. While the effects due to sex were nonsignificant ( $p>.05$ ), the main effects due to test dose and IRT bin were significant $(p<.05)$. The analysis also revealed a significant Test Dose by Sex interaction, which led to an analysis of the simple main effects. Table 2 shows the results of the simple main effects analysis for differences between drug doses at each of the 11 IRT bins for each sex.

\section{EXPERIMENT II}

The central stimulation effects of amphetamine on gross motor activity have been investigated extensively in rats (Chadel, Cho, \& McDonald, 1966; Holland \& Gupta, 1967; Marriott, 1968; Van Rossum \& Simsons, 1969). At moderate test doses, amphetamine enhances locomotor activity. It could be argued, therefore, that in Experiment I the facilitation of acquisition by amphetamine was produced by an increase in locomotor activity rather than by a change in some other mechanism, such as timing. In an attempt to differentiate simple activation and increased motor activity from other effects, such as improved timing, a second experiment was conducted. This study attempted to discover if amphetamine doses which facilitated acquisition rates in Experiment I covary with doses which enhance locomotor activity. Experiment II investigated the dose-response effects of amphetamine on gross motility levels in male and female rats.

\section{Method}

Subjects. Seventy-two naive male and female rats (Wistar descendents) were employed. The age, weight range, and housing conditions were the same as those described in Experiment I.

Apparatus. An electronic motility meter (fc 40, Motron Produkter, Stockholm, Sweden) which contained 40 photoconductive sensors, covering an area $20 \times 36 \mathrm{~cm}$, was used to measure activity. A Plexiglas activity chamber $(20 \times 36 \times 21 \mathrm{~cm})$ was placed over the meter and was illuminated from above by incadescent lamps. Each movement of an animal which changed illumination of a sensor was recorded on an Elmeg counter. The motility meter, activity chamber, and incandescent lamps were mounted in a sound-attenuated, ventilated box.

Procedure. In the motility experiment, all animals were selected and grouped in a manner identical to that employed in Experiment I. Ten minutes following drug injection, however, each animal was placed in the Plexiglas activity chamber for $2 \mathrm{~h}$. Responses during each 1-min interval and total responses during each testing period were recorded.

\section{Results}

Figure 2 shows that motility rates increased as amphetamine dose increased, with the greatest activity occurring following the $10.0-\mathrm{mg} / \mathrm{kg}$ injection. The number of motility counts for the 0.1 and $0.3 \mathrm{mg} / \mathrm{kg}$ drug-dose groups, which are not shown in Fig. 2, fell between the saline and the $3.0 \mathrm{mg} / \mathrm{kg}$ drug group Motility rates for saline, $0.1,0.3,1.0,3.0$, and $10.0 \mathrm{mg} / \mathrm{kg}$ amphetamine groups were analyzed by means of a two-factor analysis of variance. The factors considered were (a) sex and (b) test dose.

The analysis indicated a significant $(F=27.45$, df $=1 / 56, p<.001$ ) test-dose effect. The sex factor and interaction for the motility data were nonsignificant ( $p$.05). A Duncan's multiple-range test indicated that the $10.0-\mathrm{mg} / \mathrm{kg}$-drug-dose group facilitated activity significantly $(p<.01)$ more than all other test drug injections.

\section{Discussion}

These results extend previous reports (Verhave, 1958; Domino et al, 1965; Kulkarni, 1968; Stenn \& Milner, 1971) which indicate that low to moderate doses of amphetamine increase response rates during acquisition of an avoidance task, while high doses depress response rates in male rats. The present investigation indicates that certain test doses of amphetamine can produce significant increases in shock avoidance without significantly changing response rates. The data also

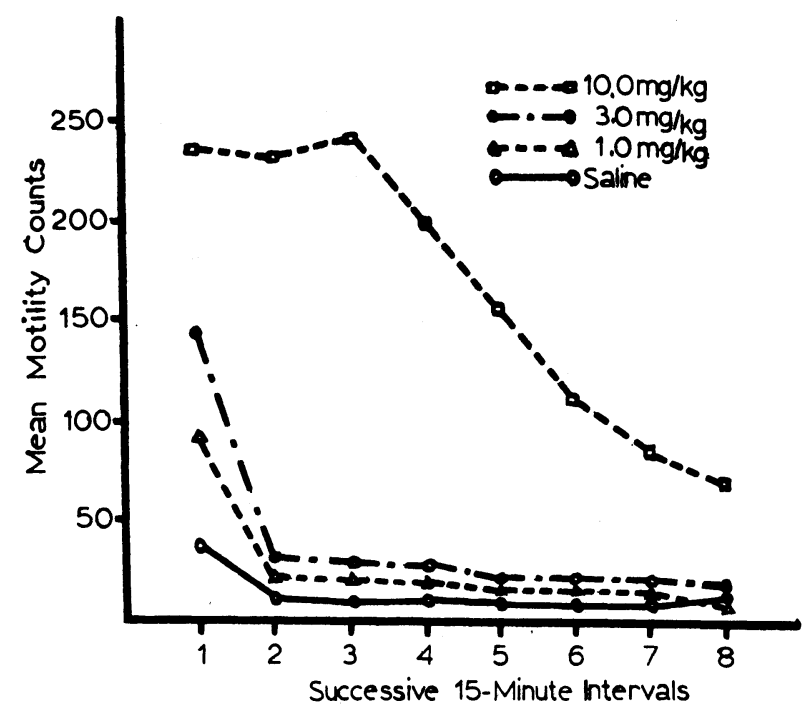

Fig. 2. Mean motor activity as a function of saline and amphetamine dose. 
demonstrate that sex, as well as drug dose, may be important in determining the effects of amphetamine upon acquisition. The analysis of the IRT data indicated both a significant test-dose effect and Dose by Sex interaction. Inspection of the IRT raw data in Table 1 and the simple effects analysis in Table 2 indicate that female rats, relative to male rats, emitted a greater number of well-timed responses, with no significant "bursting" of responses (see Table 1 and Table 2, Bin 1) and that these responses were dose-dependent.

Another question in the present study concerned the mechanism by which amphetamine altered the acquisition rates of the avoidance response. Two aspects of the data are related to this issue: (1) the interresponse times (IRT) during acquisition, and (2) the motility results. IRT analysis indicated that certain doses of amphetamine affect timing. For example, the $1.0-\mathrm{mg} / \mathrm{kg}$-amphetamine dose, the dose which produced the fewest shocks, produced the largest number of responses in Bins 6-10 (well-timed responses). In addition, the $1.0-\mathrm{mg} / \mathrm{kg}$-dose group did not differ significantly in the number of responses in Bin 1 ("bursting" responses), relative to the saline group. The increase in the number of well-timed responses and the lack of any marked change in "bursting" rates demonstrate that the amphetamine effects were not simply the result of increased motor activity. That is, if amphetamine was simply increasing activity, an increase in the "bursting" of response rates or repetitive stereotypic motor activity might be expected.

Analysis of the motility data indicates that increases in motor activity across amphetamine doses did not covary with drug-induced changes in acquisition rates. Further, sex differences were not observed in the motility experiment, while sex differences were found in the acquisition study. Thus, IRT analysis and motility data provide evidence that suggests some mechanism other than increased motor activity, such as improved timing, is involved in a dose-and-sex-related manner in amphetamine's facilitation of shock avoidance.

At present, it is not known what neurochemical systems in the brain mediate the acquisition of an avoidance task. Pharmacological data, however, indicate that amphetamine increases the release and prevents the reuptake of catecholamines in the adrenergic system (McKenzie \& Szerb, 1968; Carr \& Moore, 1970). Thus, during the acquisition periods in Experiment I, the brain levels of free, unbound norepinephrine and epinephrine may have increased and been available to activate postsynaptic sites. This suggests that the release of catecholamines is important during the acquisition of an avoidance response.

In support of this view, Brady (1967) has reported that, during classical and instrumental aversive training, there was an extensive release of norepinephrine in monkeys. Wenzel (1968) inhibited the nerve growth of sympathetic neurons in newborn mice. His procedures decreased the levels of norepinephrine in the sympathetic system and produced an inhibition of escape and avoidance acquisition in adult mice. Di Giusto, Cairncross, and King (1971) and Di Giusto (1972) have suggested that there exists a physiological system involving catecholamines, ACTH, and adrenal steroids which affects aversively motivated behavior, such as avoidance.

In summary, the present study reports data which suggest that adrenergic systems are involved in the acquisition of an avoidance response. If a complex biochemical system of neurochemicals and steroids are involved, as suggested by Di Giusto and his associates $(1971,1972)$, the differences between the male and female IRTs may be explained. That is, sex differences could be related to the presence of different sex steroids.

\section{REFERENCES}

Bolles, R. C., \& Popp, R. J. Parameters affecting acquisition of Sidman avoidance. Journal of Experimental Analysis of Behavior, 1964, 7, 315-321.

Bovet, D., \& Gatti, L. Pharmacology of instrumental avoidance conditioning. In M. Y. Michelson and V. G. Longo (Ed.), Pharmacology of conditioning, learning and retention. New York: Pergamon, 1965. Pp. 75-89.

Brady, J. V. Emotion and the sensitivity of psychoendocrine systems. In D. C. Glass (Ed.), Neurophysiology and emotion. New York: Rockefeller University Press, 1967.

Carr, L. A., \& Moore, K. E. Distribution and metabolism of norepinephrine after its administration into the cerebroventricular system of the cat. Biochemical Pharmacology, 1970, 18, 1907-1918.

Chadel, C. E., Cho, M. H., \& McDonald, R. D. The effect of amphetamine and catecholamines on startle response and motor activity of rats. Nature, 1966, 210, 864-865.

Di Giusto, E. L. Adrenaline or peripheral noradrenaline depletion and passive avoidance in the rat. Physiology \& Behavior, 1972, 8, 1059-1062.

Di Gusto, E. L., Cairncross, K., \& King, M. G. Hormonal influences on fear motivated responses. Psychological Bulletin, $1971,75,432-444$.

Dispensa, J., \& Barrett, M. E. The effect of amphetamine (benzedrine) sulfate on maze performance of the albino rat. Journal of Psychology, 1941, 11, 397-410.

Domino, E. F., Caldwell, D. F., \& Henke, R. Effects of psychoactive agents on acquisition of conditioned pole jumping in rats. Psychopharmacologia, 1965, 8, 285-289.

Doty, B., \& Doty, L. Facilitation effects of amphetamine on avoidance conditioning in relation to age and problem difficulty. Psychopharmacologia, 1966, 9, 234-241.

Evangelista, A. M., \& Izquierdo, I. The effect of pre- and post-trial amphetamine injections on avoidance responses in rats. Psychopharmacologia, 1971, 20, 42-47.

Holland, H. C., \& Gupta, B. D. The effects of some central and autonomic nervous system stimulant and depressant drugs on one form of exploratory activity in rats. Life Science, 1967, 6, 63-70.

Kulkarni, A. S. Facilitation of instrumental avoidance learning by amphetamine: An analysis. Psychopharmacologia, 1968, 13, 418-425.

Marriott, A. S. The effects of amphetamine, caffeine and methyphenidate on locomotor activity of rats in an unfamiliar environment. Internation Journal of Neuropharmacology, $1968,7,487-491$.

McKenzie, G. M., \& Szerb, J. C. The effect of dihydroxyph,enylalani e, pheniprazine, and dextroamphetamine on the in vivo release of dopamine from the caudate nucleus (cat). Journal of Pharmacology \& Experimental Therapeutics, 1968, 162, 302-308.

Minkowsky, W. L. The effect of benzedrine sulfate upon learning. Journal of Comparative Psychology, 1939, 28, 349-360.

Powell, B. J., Martin, L. K., \& Kamano, D. K. Failure to find improved shuttle box avoidance performance using d-amphetamine sulfate. Psychological Reports, 1965, 17, 330

Quarton, G. C. The enhancement of learning by drugs and the transfer of learning by macromolecules. In G. C. Quarton, T. Melnechuk, and F. O. Schmitt (Eds.), The neurosciences. New York: Rockefeller University Press, 1967, 744-755. 
Steel, R. G. D., \& Torrie, J. H. Principles and procedures of statistics. New York: McGraw-Hill, 1960.

Stenn, P. G., \& Milner, J. S. Effects of d-amphetamine upon acquisition of Sidman avoidance task in the rat. Paper presented at the meeting of the Southwestern Psychological Association, San Antonio, A pril 1971.

Van Rossum, J. M., \& Simons, F. Locomotor activity and a nor exogenic action. Psychopharmacologia, 1969, 11, 300-310.

Verhave, T. The effect of methamphetamine on operant level and avoidance behavior. Journal of Experimental Analysis of Behavior, 1958, 1, 207-219.
Wenzel, B. M. Behavioral studies of immunosympathectomized mice, Journal of Comparative \& Physiological Psychology, 1968, 66, 354-362.

Winer, B. J. Statistical principles in experimental design. New York: McGraw-Hill, 1962.

(Received for publication A ugust 27, 1973; revision received June 4, 1974.) 